\title{
Lasers - A Benefaction to Implant Dentistry
}

\author{
${ }^{1}$ Dr.Aman Arora, ${ }^{2}$ Dr.Viram Upadhyaya, ${ }^{3}$ Dr Rupa Munjal, ${ }^{4}$ Dr Divya Malik, \\ ${ }^{5}$ Dr Kirti Parashar \\ ${ }^{1}$ M.D.S (Head of Department), ${ }^{2}$ M.D.S (Reader), ${ }^{3}$ M.D.S (PG Student), ${ }^{4,5}$ (PG student)
}

\begin{abstract}
Lasers have been used for many years in implant dentistry. In some indications, laser treatment has become state of the art as compared to conventional techniques. The use of surgical lasers has been advocated to aid in the placement and second stage recovery of dental implants, together with soft tissue contouring. In addition, laser use has been suggested as an aid in decontamination of the implant surface in cases of periimplantitis. Lasers also have helped clinicians to overcome several complications and patient's discomfort. Today, many types of lasers wavelengths are available for clinical usage. The aim of this article is to introduce the reader to laser application in implant dentistry and address many of the advantages of this type of treatment. This article is a comprehensive review of new laser applications in implant dentistry.
\end{abstract}

Key Words: Lasers, implants, osteotomy, laser welding.

\section{Introduction}

The origins of implant dentistry can be traced back to China 4000 years ago when bamboo was inserted into the jaw bone for fixed tooth replacements ${ }^{1}$. Goldberg and Ghershkoff in $1949^{2}$ marked the beginning of modern implant dentistry, with the description of the technique for the subperiosteal implant. In 1985, the publication of Tissue- Integrated Prostheses: Osseointegration in Clinical Dentistry by Branemark et $\mathrm{al}^{3}$ ushered in the era of osseointegration. They introduced the concept of gental surgical insertion technique for placement of highly biocompatible titanium implants.

The province of prosthododntics has come a long way from the domain of replacing missing teeth by complicated and time consuming mechanical procedures to inexhaustable and boundless generation of modern technology. One such technology that has been a cutting edge in the field of prosthodontics is Lasers. Laser is the acronym for "Light Amplification by stimulated emission of radiation" named by GORDON GOULD in $1957^{4}$. In 1960, Theodore Maiman ${ }^{5}$, a scientist with the Hughes Aircraft Corporation, developed the first working laser device, which emitted a deep red-colored beam from a ruby crystal. During the next few years, dental researchers studied possible applications of this visible laser energy

Studies in the 1970s and 1980s turned to other devices, such as CO2 and neodymium YAG (Nd:YAG), which were thought to have better interaction with dental hard tissues. The medical community in the mid to late 1970s had begun to incorporate lasers for soft-tissue procedures, and oral surgeons added the technology in the early 1980s. Frame ${ }^{6}$, Pecaro $^{7}$, and Pick $^{8}$ cited the benefits of CO2 laser treatment of oral soft-tissue lesions and periodontal procedures.

In 1990, Myers and Myers ${ }^{9}$ received the US Food and Drug Administration's permission to sell a dedicated dental laser, a Nd:YAG device for intraoral soft tissue surgery. In time other laser wavelengths such as Argon, Ho:YAG and Er:YAG laser was investigated and numerous instruments have been made available for use in dental practice and more are being developed ${ }^{10,11}$. Both lasers and implantology are considered to

be the fashionable treatments of modern dentistry, and combining them seems to represent best practice from a number of perspectives. Implantology is one of the many dental indications for the use of lasers, and it is one from which patients can benefit significantly. many laser wavelengths have become available and have gained popularity in different aspects of dentistry. Recently, the use of laser systems has become increasingly popular in dental implantology.

Depending Upon The Wavelength:

\section{Laser Types}

\begin{tabular}{|l|l|l|}
\hline \multicolumn{1}{|c|}{ Light Source } & \multicolumn{1}{c|}{ Wavelength } & \multicolumn{1}{c|}{ Use } \\
\hline UV Light & $100 \mathrm{~nm}-400 \mathrm{~nm}$ & Not used in dentistry \\
\hline Visible Light & $400 \mathrm{~nm}-750 \mathrm{~nm}$ & Most commonly used in dentistry e.g Argonand Diagnogent laser \\
\hline Infra-red & $750-100000$ & Most dental lasers are in this spectrum \\
\hline
\end{tabular}

Depending Upon Duration Of Laser Emission:

- Continuous wave $(\mathrm{CW})$

- Single pulsed (normal mode) lasers 
- Single pulsed q-switched lasers

- Repetitively pulsed or scanning lasers

- Mode locked lasers

Depending Upon The Tissue They Penetrate:

\begin{tabular}{|l|l|}
\hline TYPE OF LASER & EXAMPLE \\
\hline Soft tissue laser & KTP ,Diode, Nd:YAG, $\mathrm{CO}_{2}$ \\
\hline Hard and Soft Tissue Lasers & Er:YAG, Er:Cr:YSSG \\
\hline
\end{tabular}

\section{Depending Upon Hardness:}

Soft Lasers: With a wave length around $632 \mathrm{~mm}$. Soft lasers are lower power lasers. These soft lasers generally utilize diodes and the manufacturers claim that these lasers can aid healing of the tissue, reduces inflammation, edema, and pain.

- Helium-neon (He-N) at $632.8 \mathrm{~nm}$ (red, visible).

- Gallium- arsenide (Ga-As) at $830 \mathrm{~nm}$ (infra-red, invisible).

HARD LASERS (Surgical lasers) : Hard lasers induce a direct reaction with tissue through absorption. They are used in surgery, for germ and bacteria reduction.

- Argon lasers (Ar) at 488 to $514 \mathrm{~nm}$

- Carbon-dioxide lasers (CO2) at 10.6 micro-meter

- Neodymium-doped yttrium aluminum garnet (Nd:YAG) at 1.064 micrometer.

- Holmiumyttrium-aluminum-garnet (Ho:YAG) at 2.1 micro-meter.

- Erbium,chromiummyttrium-slenium-gallium-garnet (Er,Cr:YSGG) at 2.78 micro-meter.

- Neodymiummyttrium-aluminum-perovskite (Nd:YAP) at 1,340 nm.

Depending Upon The Type Of Active / Lasing Medium Used :

Solid State Laser: In this kind of laserss solid state materials are used as active medium. The solid state materials can be ruby, neodymium-YAG (yttrium aluminum garnet), Er:YAG, Er:Cr:YSGG.

Gas Laser: These LASERs contain a mixture of helium and Neon. It acts as active medium. $\mathrm{CO}_{2}$ and Nitrogen LASER can also be made.

Dye or Liquid Laser: In this kind of LASERs organic dyes like Rhodamine $6 \mathrm{G}$ in liquid solution or suspension used as active medium inside the glass tube.

Excimer Laser: Excimer Lasers (the name came from excited and dimers) use reactive gases like Chlorine and fluorine mixed with inert gases like Argon or Krypton or Xenon. This LASERs produce light in the ultraviolet range.

Chemical LASER: A chemical laser is a laser that obtains its energy from a chemical reaction. Examples of chemical lasers are the chemical oxygen iodine laser (COIL), all gas-phase iodine laser (AGIL), and the hydrogen fluoride laser, deuterium fluoride laser etc.

Semiconductor LASER: In these lasers, junction diodes are used. These are known as injection laser diodes. Whenever the current is passed, light can be seen at the output.

\section{Classification Of Lasers:}

According to ANSI and OHSA standards lasers are classified as:

Class I- These are low powered lasers that are safe to use. e.g. Laser beam pointer

Class II- Low powered visible lasers that are hazardous only when viewed directly for longer than 1000 seconds, e.g. He-Ne lasers

Class II b - Low powered visible lasers that are hazardous when viewed for more than 0.25 seconds.

Class III a - Medium powered lasers that are normally hazardous if viewed for less than 0.25 seconds without magnifying optics.

Class III b - Medium powered lasers that can be hazardous if viewed directly.

Class IV - These are high powered lasers $(>0.5 \mathrm{~W})$ that produce ocular skin and fire hazards.

Advantages of Lasers ${ }^{12}$ :

- It is painless, bloodless that results in clean surgical field, and fine incision with precision is possible.

- There is no need for anaesthesia if at all anaesthesia has to be administered, then it needs to be used minimally only.

- The risk of infection is reduced as a more sterilized environment is created as the laser kills bacteria.

- No postoperative discomfort, minima lpain and swelling, generally doesn't require medication.

- Superior and faster healing, offers better patient compliance. 
Disadvantages of Lasers ${ }^{13}$ :

- Lasers cannot be used to remove defective crowns or silver fillings, or to prepare teeth for bridges.

- $\quad$ Lasers can't be used on teeth with filling already in place.

- Lasers don't completely eliminate the need for anaesthesia.

- Lasers treatment is more expensive as the cost of the laser equipment itself is much higher

\section{Characteristics of Lasers Used In Implantology:} $\mathrm{CO}_{2}$ LASER:

CO2 laser was first time developed by Patel et al. in $1964^{14}$. CO2 laser have a wave length of 10.6 microns, are gas and fall into the far infra-red into the spectrum. All $\mathrm{CO}_{2}$ lasers works in non-contact mode. $\mathrm{CO}_{2}$ lasers have an affinity for wet tissues regardless of tissue color. They are highly absorbed in oral mucosa, which is more than $90 \%$ water, although their penetration depth is only about 0.2 to $0.1 \mathrm{~mm}$. There is no scattering, reflection, or transmission in oral mucosa. Hence, what you see is what you get. $\mathrm{CO}_{2}$ lasers reflect off mirrors, allowing access to difficult areas. Unfortunately, they also reflect off dental instruments, making accidental reflection to non-target tissue a concern. As $\mathrm{CO}_{2}$ lasers are invisible, an aiming helium - neon (He $\mathrm{Ne}$ ) beam must be used in conjunction with this laser. One of the limitation of this laser is the penetration depth is approximately 0.2 to $0.3 \mathrm{~mm}$.

\section{Nd: YAG Laser:}

Here a crystal of Yttrium - aluminum - garnet is doped with neodymium. Nd: YAG laser, has wavelength of 1,064 $\mathrm{nm}(0.106)$ placing it in the near infrared range of the magnetic spectrum. Nd:YAG laser was first developed by Geusic in 1964. A crystal of yttrium-aluminum- garnet doped with neodymium is used and they are invisible similar to CO2 laser, have infra-red range on spectrum. It is not well absorbed by water but are attracted to pigmented tissue. Eg: hemoglobin and melanin. Therefore various degrees of optical scattering and penetration to the tissue, minimal absorption and no reflection. Most dental Nd: YAG lasers work in a pulsed mode. At higher powers and pulsing, a super heated gas called a plasma can form on the tissue surface. It is the plasma that can be responsible for the effects of either coagulation, vaporization or cutting. If not cooled (e.g. by running a water stream down the fiber) the plasma can cause damage to the surrounding tissues.

DIODE LASER: Indium-Gallium-Arsenide-Phosphide-Ingaasp (Diode); Gallium-Aluminum-ArsenideGaalas (Diode); Gallium-Arsenide - Gaas(Diode) :

It has wavelength range of 635 to $950 \mathrm{~nm}$, utilizing flexible quartz fiber; it is absorbed by pigmentation of the soft tissue. Thereby making diode laser an excellent hemostatic agent. Diode is used for soft tissue removal in contact mode, giving tactile sensation similar to electro cautery. Tissue penetration is less than comparable Nd:YAG effects, with potential for heat damage to underlying bone reduction ${ }^{15,16}$. The Nd:YAG beam is readily absorbed by amalgam, titanium and non-precious metals, requiring careful operation in the presence of these dental materials. The depth of penetration has been estimated to be $2+_{-} 1 \mathrm{~mm}$ in soft tissue.

\section{ARGON LASERS:}

Argon lasers are those lasers in the blue-green visible spectrum. They operate at $488 \mathrm{~nm}$ or $514.5 \mathrm{~nm}$, are gas like $\mathrm{CO}_{2}$ lasers and are easily delivered fiber optically like Nd:YAG. Argon lasers have an affinity for darker colored tissues and also a high affinity for hemoglobin, making them excellent coagulators. It is not absorbed well by hard tissue, and no particular care is needed to protect the teeth during surgery. The blue wavelength of $488 \mathrm{~nm}$ is used mainly for composite curing, while green wavelength of $510 \mathrm{~nm}$ is mainly for the soft tissue procedures and coagulation ${ }^{17}$.

\section{ERBIUM:YAG LASER:}

In 1997 with FDA safety clearance erbium: YAG laser have been practiced on hard tissue like enamel, cementum, bone. Er:YAG laser has not been extensively used for the soft tissue applications. Helium neon laser is utilized as aiming beam in the fiber optic delivery system. Er:YAG laser has a wavelength of 2,940 nm, which is said to be ideal for absorption by hydroxyapatite crystals and water. This wavelength causes water to evaporate into steam, being irradiated resulting micro-explosion of the hard tissue ${ }^{18}$. Water spray is used to wet the surface during laser radiation to achieve maximum efficiency of tissue removal with minimum heat generation.

Er:Cr:YSGG LASER (Erbium: Chromium: YSGG): Also known as water-laser (marketed as Bio-laser in the USA), works by Hydro-kinetic tissue cutting system using laser power to energize water for the use on hard and soft tissues. 
Ho: YAG LASER (Holmium YAG lasers): It has a wavelength of 2,100 $\mathrm{nm}$ and is a crystal. It is delivered through a fiber optic carrier and a He-Ne laser is used as an aiming light. Like Nd: YAG, can be used in both the contact and non-contact modes and are pulsed lasers. Ho: YAG laser has an affinity for white tissue and has ability to pass through water and acts as a good coagulator.

\section{Use Of Lasers In Removal Of Granulation Tissue Prior To Implant Placement}

One of the most important uses of lasers in implantology is the removal of granulation tissue and disinfection of the surgical area after extraction. Erbium lasers can be used for this purpose, especially if there was chronic infection before the extraction, regardless of whether implants or bone grafts are being placed. It has even been suggested that implants can be placed at pre-infected sites, although the site has to be cleaned thoroughly. Owing to significant differences in water content, the erbium laser can be used to only remove soft tissue by setting the parameters correctly (energy density, pulse duration, etc.). This is done without thermal side-effects on the bone, and with greater comfort to the patient while disinfecting the surface, since no force is applied, unlike with curettes.

\section{Lasers as Haemostats}

A good percentage of older patients are on anticoagulant therapy because of some cardiological conditions. In such cases laser hemostasis is a boon over conventional techniques. Nd:YAG has been very effective in this field as it has penetration depth of $4 \mathrm{~mm}$ in soft tissues. In a clinical study in 44 patients by Horch and Deppe ${ }^{19}$, bare laser technique was used, and to reduce the thermal effects, a pulsed laser was used. It was concluded that intra-alveolar application of pulsed Nd:YAG laser energy can be considered safe.

\section{Laser Aided Osteotomy}

Traditionally used techniques in bone removal have involved handpieces, bone files, etc. But, now precise bone cutting can be obtained with with the Er:YAG laser and CO2 laser. Lasers can not only be used to establish a controlled incision of overlying gingival tissue and to initiate a breach of the cortical bone plate, prior to the use of conventional implant drills but can also be used to prepare osteotomy site, where,there is no need for exertion of pressure on the bone, which could be an advantage when performing an osteotomy. The cause of concern while performing osteotomy is rise of temperature and bone implant contact after implant placement. During osteotomy procedures, an increase in temperature of the bone increases the risk for developing postoperative complications. Possibility of overheating the bone is high when conventional drill systems are used due to difficulty in getting the coolant between the drill and the bone ${ }^{20}$.

Eyrich $\mathrm{G}^{21}$ compared the super-pulsed $\mathrm{CO} 2$ laser at $9.6 \mu \mathrm{m}$ to the Er-YAG laser and the conventional drill with regard to their respective thermal effects on human bone. Therefore, temperature rise during ablation of human bone was measured. The results of the study suggested that a maximum rise of mean temperature to $1.88^{\circ} \mathrm{C}$ (well below the critical range of $7^{\circ} \mathrm{C}$ ) demonstrated the safety and tissue-preserving capability of the super-pulsed 9.6- $\mu \mathrm{m} \mathrm{CO} 2$ laser. Stübinger $\mathrm{S}$ et $\mathrm{al}^{22}$ examined the influence of implant bed preparation, using either Er:YAG laser ablation, piezoelectric surgery or drill osteotomy, on osseointegration of titanium dental implants after 4, 6, and 8 weeks and found that BIC in laser and piezoelectric osteotomy seem to be at least comparable to drill osteotomy.

\section{Use of Lasers In Second Stage Uncovering Of Implants}

The most friendly laser that can be for uncovering of implants is Er:YAG laser . Using a reduced water spray in order to decrease bleeding, it is possible to uncover the implant with diminished pain, even if bone is covering the implant. Using longer pulses causes haemostasis in the soft tissue, while shorter pulses enable the removal of bone without thermal side-effects. This is achieved without causing pain to the patient and without raising a flap. This is possible, of course, if there is sufficient attached gingiva and the crestal attached gingiva does not need to be replaced apically. When there is no harmful heating of the soft tissue, there is no retraction of tissue, so the impressions can be taken as soon as possible without delay.

Kurtzman GM presented a case report in which diode laser at $2.5 \mathrm{~W}$ in continous mode was used in a circular motion, moving outwards until the entire cover screw was exposed (Figure 1).

The Diode Laser as an Adjunct to Implant Treatment

Safe cutting and hemostasis for improved workflow and outcomes Gregori M. Kurtzman,Inside Dentistry .2015;11(7):72-5.) 


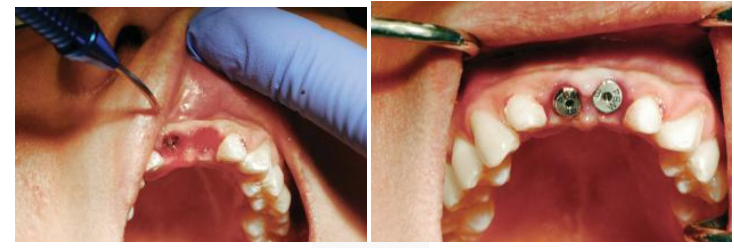

Figure 1

\section{Use Of Lasers For Decontamination Of Implant Surface}

A new indication of laser treatment might be the sterilisation of exposed implant surfaces to rehabilitate ailing implants. The laser systems that are effectively used for this purpose are $\mathrm{CO} 2$ laser and Er:YAG laser. Nd:YAG lasers have produced in vitro undesirable results, such as melting and increasing the roughness of the implant surface. Although Nd: YAG lasers significantly decrease bacteria, alterations to the implant structure occurred as well as significant increases in temperature ${ }^{23}$. For these reasons, the application of the contact $\mathrm{Nd}$ :YAG laser for treatment of periimplantitis is contraindicated. In contrast to that, $\mathrm{CO} 2$ lasers at a low-power setting are advantageous for periimplant procedures. They provide disinfection and significant bacterial reduction without causing any alteration to the implant structure.

A study by Deppe et $\mathrm{al}^{24}$ compared $\mathrm{CO} 2$ laser assisted implant decontamination vs conventional decontamination procedures. This study showed that limplants treated with $\mathrm{CO} 2$ laser decontamination exhibited statistically significant better clinical parameters than conventionally decontaminated implants.

Promising results in the treatment of periimplantitis have also been demonstrated histologically by Takasaki et $\mathrm{al}^{25}$ in their study compared the effect of Er:YAG laserntional curettage on the periimplantitis and concluded that and conv. The study showed better results with a greater boneto- implant contact percentages are obtained using using the Er:YAG laser compared with the curette group. Kreisler et $a^{26}$ evaluated different lasers \{Nd:YAG, Ho:YAG, Er:YAG, CO2, and diode (gallium-aluminum-arsenide)\}for implant decontamination. They concluded that Nd:YAG and Ho:YAG were not suitable for implant surface decontamination as they caused changes in the surface layers of implants and that CO2 and Er:YAG could be used at low-power settings to avoid surface alterations, whereas gallium-aluminum-arsenide lasers did not cause surface changes.

Figure - shows decontamination of implant surface with Nd:YAG laser and Fig2 shows radiograph before the laser treatment and radiograph after the laser treatment of the same implant.

(The use of laser therapy for dental implant surface decontamination: a narrative review of in vitro studies. Lasers Med Sci. 2014 Nov;29(6):1977-85

Kamel MS, Khosa A, Tawse-Smith A, Leichter J.)

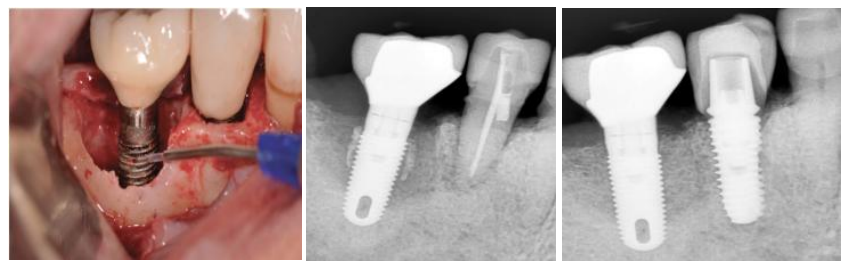

Figure 2

\section{Laser Welding Of Implant Supported Metal Frameworks}

The application of laser welding technology allows titanium to be welded predictably and precisely to achieve accurate fit of a milled framework. Laser energy results in localized heat production, thereby reducing thermal expansion. Unlike soldering, laser energy can be directed to a small area, making it possible to laser weld close to acrylic resin or ceramic. Neodynium:YAG (Nd:YAG) lasers are solid active medium lasers frequently used in dentistry to weld dental alloys. Advantages of laser welding include: (1) laser-welded joints are stronger than soldered joints; (2) localized heat is produced, thus avoiding expansion and distortion; (3) the need to fabricate a refractory cast is eliminated; (4) welding can be performed in close proximity with acrylic resin or ceramics ${ }^{27,28}$. In one of the studies performed by Fornani $\mathrm{C}$ et al, two techniques to weld metals intraorally, the Nd:YAG laser welding and resistance spot welding, were compared for temperature rise in titanium bars and titanium implants during welding processand for the strength of soldered joint by two methods. The results confirmed that there is minimumrise in temperature with laser welding and also that strength of joint is more in laser welded implant framework ${ }^{29}$. Reidy et $\mathrm{al}^{30}$ have also reported the precision, fit of the laser-welded framework to 1-piece casting. A study by Bergendal and Plamqvist ${ }^{31}$ documented more fractures of artificial teeth on titanium-welded frameworks. 


\section{Laser Applications In The Dental Laboratory}

Lasers have been used for deposition of hydroxyapatite (HA) thin films on titanium implants. Pulsed laser deposition (PLD) has proven to be a promising method to produce pure, crystalline and adherent HA coatings which show no dissolution in a simulated body fluid. Use of lasers for surface treatment of titanium castings for ceramic bonding have shown improved bond strength when compared to acid etching techniques which are commonly used.

Ayako et al applied our laser-assisted biomimetic (LAB) process to successfully achieve rapid single-step CaP precipitation on the surface of titanium metal, which is an important metallic biomaterial, by applying pulsed laser irradiation to the titanium substrate immersed in a supersaturated $\mathrm{CaP}$ solution. Precipitation occurred via the combined effect of laser surface modification and ambient heating.

(Laser-assisted biomimetic process for surface functionalization of titanium metal .Ayako Oyane a, Nao Matsuoka, Kenji Koga ,Yoshiki Shimizua, Maki Nakamura, Kenji Kawaguchi , Naoto Koshizaki , Yu Sogo , Atsuo Ito , Hidero Unuma . Colloids and Interface Science Communications.)

Energy Dispersive X-ray Analysis revealed that calcium and phosphate were detected after conducting LAB process(Fig 1a). Scanning electron microscopic images in Fig 1b showed that titanium surface deformed into a microscale grainy structure with sub-microscale asperity faces after conducting Laser Assisted Biometric (LAB) process.

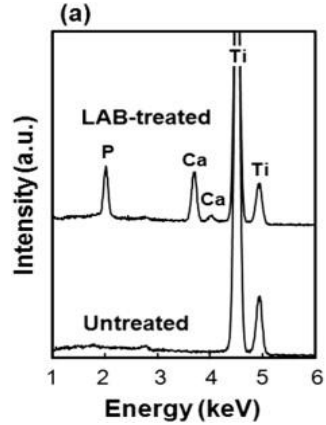

(b)

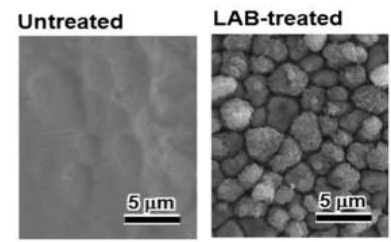

Fig. 3 Energy-dispersive X-ray analysis (EDX) spectra and (b) scanning electron microscopy (SEM) images of the untreated titanium substrate surface and that after conducting the LAB process

Jin-Tae Kim et al compared the effect of laser etching ,machining, airborne-particle abrasion, and acid etching on the bond strength between a titanium substrate and porcelain and concluded that the laser-etching surface treatment improves bond strength to a low fusing porcelain more as compared to acid-etching and machining surface treatment methods but was comparable in results to air abrasion method. The photomicrographs of the metal surface after debonding are presented in Figure All of the experimental groups exhibited small amounts of porcelain retained on the surface but airborne particle abraded and laser etched showed more of the porcelain attached to the metal surface.
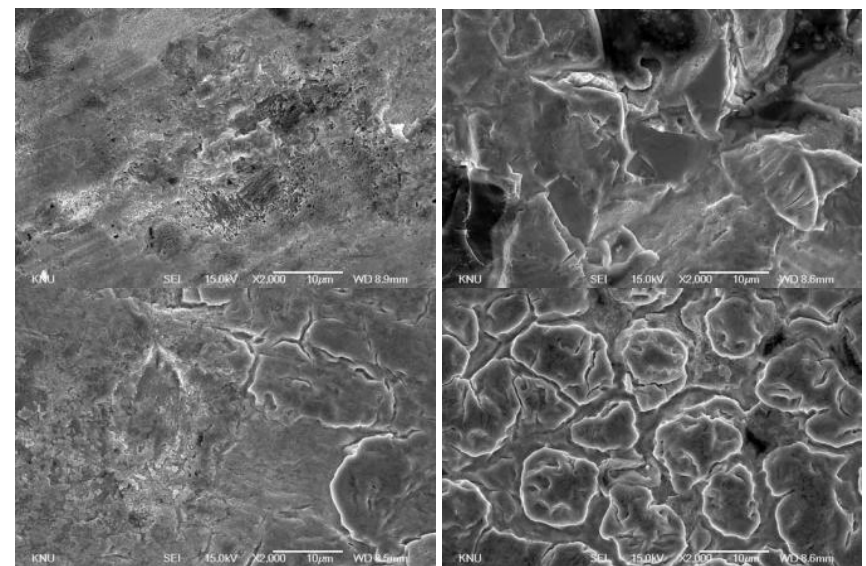

Figure 4: SEM photomicrographs of fractured metal surfaces after shear bond test.A-Machined, B-Air borne particle abraded, C-Acid etched, D-Laser etched.

(The effects of laser etching on shear bond strength at the titanium ceramic interface .Jin-Tae Kim, DDS,a and Sung-Am Cho . J Prosthet Dent. 2009 Feb;101(2):101-6.) 


\section{Conclusion}

Lasers have become a ray of hope in dentistry. Lasers have made a tremendous impact on the delivery of dental care and will continue to do so as the technology continues to improve and evolve. When used effectively and ethically, lasers are an exceptional modality of treatment for many clinical conditions that dentists treat on a daily basis. The results of implant procedures carried out with lasers seem to be promising only when correct laser with correct wavelength and power settings is used. Not only this, the clinician should have extensive knowledge of laser physics and laser tissue interactions before any laser treatment is carried out. Lasers have made a tremendous impact on the delivery of dental care and will continue to do so as the technology continues to improve and evolve. Lasers can prove to be a blessing in disguise if used safely and properly

\section{References}

[1]. Cranin AN, Klein M, Simons A. Atlas of oral implantology. 2nd edition. St. Louis (MO): Mosby; 1999. p. vii.

[2]. Goldberg NI, Gershkoff A. The implant lower denture. Dent Abstr 1949;55:490-3

[3]. Branemark PI, Zarb GA, Albrektsson T. Tissue-integrated prostheses: osseointegration in clinical dentistry. Chicago: Quintessence Publishing; 1985.

[4]. Walsh LJ. The current status of laser applications in dentistry. Aust Dent J 2003;48(3):146-55.

[5]. Maiman T. Stimulated optical radiation in ruby. Nature 1960;187:493-4.

[6]. Frame JW. Carbon dioxide laser surgery for benign oral lesions. Br Dent J 1985;158:125-

[7]. Pecaro BC, Garehime WJ. The CO2 laser in oral and maxillofacial surgery. J Ora Maxillofac Surg 1983;41:725-8.

[8]. Pick RM, Pecaro BC, Silberman CJ. The laser gingivectomy. J Periodont 1985;56:492-4.

[9]. Myers TD (1991) Lasers in dentistry: Their application inclinical practice. J Am Dent Assoc 122:46-50.

[10]. Coluzzi DJ (2000) An overview of laser wavelengths used in dentistry. Dent Clin N Am 44:753-765.

[11]. Coluzzi DJ (2004) Fundamentals of dental lasers: science and instruments. Dent Clin N Am 48:751-770.

[12]. Walsh LJ. The current status of laser applications in dentistry. Aust Dent J 2003;48(3):146-55.

[13]. George Saira. Review of lasers in dentistry. Solaze Journal of laser dentistry. 2010; 4(2):31-2.

[14]. Patel.CKN, McFarlane.RA, Faust.WL. Selective Excitation through vibrational energy transfer and optical Maser action in N2CO2. Physiol Rev1964; 13: 617-619.

[15]. Fujii.T, Baehni.PC, Kawai.O, Kwawkami.T, Matsuda.K, Kowashi.Y. Scanning electron microscopic study of the effects of Er:YAG laser on root cementum. J Periodontol1998;69:1283-1290.

[16]. Ryden H, Bjelkhagen H, Soder PO. The use of laser beam for measuring tooth mobility and tooth movements. J Periodontol1875;46:421-425.

[17]. Pick.RM. Using Laser in clinical dental practice. J Am Dent Assoc1993;124(2):34-47.

[18]. Fujii.T, Baehni.PC, Kawai.O, Kwawkami.T, Matsuda.K, Kowashi.Y. Scanning electron microscopic study of the effects of Er:YAG laser on root cementum. J Periodontol1998;69:1283-1290.

[19]. Horch H-H, Deppe H. Laser in der Zahnärztlichen Chirurgie und Mund-, Kieferund Gesichtschirurgie. In: Berlien H-P, Müller G, eds (Hrsg.): Angew. Lasermedizin. Lehr- und Handbuch für Praxis und Klinik. Loseblatt-Ausg. Ausg. Landsberg, Ecomed, III. 3.3.1; 2004:1-28.

[20]. Keller U, Hibst R, Mohr W. Experimental animal studies on laser osteotomy using the erbium:YAG laser system [Article in German]. Dtsch Z Mund Kiefer Gesichtschir. 1991;15:197-199.

[21]. Eyrich G. Hard-Tissue Drilling and Cutting With a 9.6mm CO2 Laser. Zürich, Germany: Med. Habilitationsschrift, 2004 : 1-118.

[22]. Stübinger $S^{1}$, Biermeier K, Bächi B, Ferguson SJ, Sader R, von Rechenberg B. Comparison of Er:YAG laser, piezoelectric, and drill osteotomy for dental implant site preparation: a biomechanical and histological analysis in sheep. Lasers Surg Med. 2010 Sep;42(7):652-61.

[23]. Eyrich G. Hard-Tissue Drilling and Cutting With a 9.6mm CO2 Laser. Zürich, Germany: Med. Habilitationsschrift, $2004: 1-118$.

[24]. Chu RT, Watanabe L, White JM, Marshal JW, Marshal SJ,Hutton JE. Temperature rise and surface modificationmof lased titanium cylinders. J Dent Res. 1992;71:144, special issue, abstract No 312.

[25]. Deppe H, Horch H-H,Wagenpfeil S (2003) $\mathrm{CO}_{2}$-laser assistierte versus konventionelle Implantat-Dekontamination-Eine klinische Dreijahresstudie. Z ZahnarztlImpl 19:73-81.

[26]. Takasaki AA, Aoki A, Mizutani K, et al. Er:YAG laser therapy for peri-implant infection: A histological study. Lasers Med Sci. 2007;22:143-157.

[27]. Kreisler M, Gotz H, Duschner H. Effect of Nd: YAG, Ho: YAG, Er: YAG, CO2 and GaAIAs laser irradiation on surface of endosseous dental implants. Int J Oral Maxillofac Implants. 2002:17:202-211.)

[28]. Jackson BJ. The use of laser-welded titanium framework technology: a case report for the totally edentulous patient. J Oral Implantol 2005;31:294-300.

[29]. Liu J, Watanabi I, Yoshida K, Atsuta M. Joint strength of laser-welded titanium. Dent Mater 2002;18:143-8.

[30]. Carlo Fornaini, Marco Meleti, Mauro Bonanini, Giuseppe Lagori, Paolo Vescovi, Elisabetta Merigo, Samir Nammour. Laser Welded versus Resistance Spot Welded Bone Implants: Analysis of the Thermal Increase and Strength. ScientificWorld Journal. 2014: 1-8.

[31]. Reidy SJ, Lang BR, Lang BE. Fit of implant frameworks fabricated by different techniques. J Prosthet Dent. 1997;78:596-604.

[32]. Bergendal B, Palmqvist S. Laserwelded titanium frameworks for fixed prostheses supported by osseointegrated implants: A 2 year multicenter study report. Int J Oral Maxillofac Implants. 1995;10: 199-206. 